\title{
PERFORMANCE OF COCONUT TIMBER UNDER FIELD AND SERVICE CONDITIONS
}

By

\author{
R.N. Palomar and V.K. Sulc*
}

\section{INTRODUCTION}

Approximately 3.4 million hectares of coconut plantation arc spread ail over the coconut producing provinces in the Philippines. Of these, 50\% arc found in Mindanao, $21.1 \%$ in the Visayas and 28.9\% in Luzon including the Southern Tagalog and Bicol regions (PCA Annual Report, 1986).

It has been estimated that $30 \%$ of the area planted to coconut arc 60 years old and over. These coconut stands are considered unproductive and should be replanted with improved and high-yielding coconut varieties.

Based on 100 palms per hectare, around 100 million trees would be replanted and on the basis of sawn timber recovery of $0.25 \mathrm{~m} 3$ per tree, a total of 25 million $\mathrm{m} 3$ of coconut lumber would be immediately available for economic utilization. In a 40-year cycle replanting program, an annual supply of about 8.5 million trees with recovery of 2.125 million $\mathrm{m} 3$ of sawn timber would be realized.

The many uses of coconut timber have been successfully demonstrated at the PCA-Zamboanga Research Center. The most potential uses of this renewable material, as far as necessity and suitability arc concerned, would be in the form of round timber for power poles and sawn timber for building construction which could be utilized specifically for the government's rural electrification program and low-cost housing project.

However, the uses of coconut wood for the aforementioned purposes has always been confronted by problems with wood destroying organisms particularly decay fungi, termites and other borers. Like many conventional woods, cocowood is not naturally durable when used in situation where it is exposed to the weather and in ground contact or when it is utilized in building construction where termites and wood borers are prevalent. Experience has shown that even the hard outer portion of the trunk can be destroyed in a short period of time (6 months to one year) when it is exposed to decay-and termites-hazard situations.

The low natural durability of coconut timber can be tremendously improved by preservative treatment. Development of economic and effective process of cocowood preservation should be done to guarantee that the material is put to its intended use for reasonable service life. Parallel to this, field and service testing of the treated cocowood material should be undertaken to determine the efficacy of the treatment process as well as the economic service life of the material.

This report covers the results of assessment on the performance of coconut timber when used in ground contact and exposed conditions and in building construction.

${ }^{*}$ Chief, Timber Utilization Division, Philippine Coconut Authority, Zamboanga Research Center, Zamboanga City, Philippines and Wood Technologist and UNDP/FAO Consultant, Canberra, Australia. 


\section{FIELD TESTS}

\section{A. Stake test (Graveyard No. 1).}

This test aims to determine the field life of Chromated Copper Arsenate (CCA)-treated cocowood stakes in contact with ground at different levels of preservative retentions. The samples measuring $25 \mathrm{~mm} \times 50 \mathrm{~mm} \times 500 \mathrm{~mm}$ were prepared according to density, such as 40 pieces hard and 40 pieces soft timber. Each sample was dried to equilibrium moisture content prior to treatment. The vacuum-pressure method was employed with the following treatment schedules: first vacuum of 85 kpa, 20 minutes; pressure of $14 \mathrm{kpa}, 25$ minutes; and second vacuum, 5 minutes. Three treatment charges were made based on the CCA solution concentrations used namely: $1 \%, 2 \%$ and $3 \%$. Each charge consisted of 10 low and 10 high density materials making a total of 60 treated wood samples with different preservative retentions. The other 10 low and 10 high density samples remained untreated which served as control.

The treated sample stakes were air dried for one week before installation. Together with the control stakes, they were installed vertically at a depth of $250 \mathrm{~mm}$ from ground line following the IUFRO layout in a graveyard located at the PCA - Zamboanga Research Center. The performance of untreated and treated stakes was evaluated after ail the replicate samples were decayed or failed. The average life of a particular treatment group was determined by adding the life span of each replicate stake in month divided by 10.

Table 1. presents the CCA retention and corresponding field life of untreated and treated low and high density cocowood stakes installed under graveyard condition. Results showed that the field life of the stakes increased with increasing preservative retention. Low density materials with CCA retentions of 5.87, 11.49 and $18.67 \mathrm{~kg} / \mathrm{m} 3$ indicated mean field lives of 14.0, 23.2 and 43.2 months, respectively while the untreated samples failed after 7.5 months. Although the high density materials significantly received lower retention than the low density samples, the former performed better than the latter materials under exposed and ground contact conditions. High density stakes having preservative retentions of $4.22,8.98$ and $13.91 \mathrm{~kg} / \mathrm{m} 3$ had mean field lives of $32.5,56.9$ and 76.8 months compared with the untreated specimens which were decayed after 17.0 months.

Table 1. Field life in (in months) of untreated and treated low and high density cocowood stakes installed under graveyard condition. 1/

\begin{tabular}{|c|c|c|}
\hline TYPE OF TIMBER & $\begin{array}{c}\text { CCA RETENTION } \\
(\mathrm{kg} / \mathrm{m} 3)\end{array}$ & $\begin{array}{c}\text { FIELD LIFE } \\
\text { (month) }\end{array}$ \\
\hline \multirow{3}{*}{ Low density } & & 7.5 \\
& Control (untreated) & 14.0 \\
& 5.87 & 23.2 \\
& 11.49 & 43.2 \\
\hline High density & 18.67 & 17.0 \\
& Control (untreated) & 32.5 \\
& 4.22 & 56.9 \\
& 8.98 & 76.8 \\
\hline
\end{tabular}

1/Mean of 10 samples. 


\section{B. Stake test (Graveyard No. 2).}

This study evaluates the efficacy of different wood preservatives applied to coconut timber stakes exposed in ground contact under different locations. The stakes measuring $25 \mathrm{~mm}$ x $50 \mathrm{~mm} \times$ $500 \mathrm{~mm}$ were composed of high and medium density wood. Eleven treatments/treatment combinations were made with 4 retention levels for each high and medium density materials. Each level of preservative retention consisted of 10 sample stakes. The preservative used were CCA, Copper Sulphate, Sodium Dichromate, Arsenic Pentoxide, PQ 56, Protek Q and Penthachlorophenol. The stakes were treated by vacuum-pressure, modified double diffusion and simple diffusion methods.

The treated stakes together with control were installed at a depth of $250 \mathrm{~mm}$ from groundline in graveyards located at Albay, Davao and Zamboanga Research Centers in November, 1980. The samples were assessed semi-annually to evaluate their field performance.

Results of assessment on the performance of the cocowood stakes after 8 years in ground contact and exposed conditions arc presented in Table 2.

On the other hand, samples treated by the modified double diffusion and simple diffusion methods (non-pressure treatment) revealed that higher preservative retentions did not achieve higher field lives after all the replicate stakes failed due to decay and termites attack. This discrepancy was caused by the incomplete penetration and uneven distribution of preservative into the wood after treatment as shown by laboratory spray test resulting to early failure of the specimens even they achieved adequate preservative retention.

The highest field life so far for high density cocowood stakes treated by the modified double diffusion process (T2) with preservative retention of $1.75 \%$ a.i. was 77.9 months (6.5 years) compared to 86.1 months (7.2 years) for vacuum-pressure treatment (T1) having preservative retention of $1.72 \%$ a.i.

Table 2. Performance of coconut wood stakes after 8 years in ground contact. 1/

\begin{tabular}{|c|c|c|c|c|c|}
\hline \multirow{2}{*}{$\begin{array}{c}\text { TREATMENT } \\
\text { METHOD }\end{array}$} & \multirow{2}{*}{$\begin{array}{l}\text { Type of } \\
\text { Timber }\end{array}$} & \multirow{2}{*}{$\begin{array}{c}\text { Retention } \\
\text { (\% a.i.) }\end{array}$} & \multicolumn{3}{|c|}{ Performance Rating 2/ } \\
\hline & & & ZRC & DRC & ARC \\
\hline \multirow{8}{*}{$\begin{array}{l}\text { T1. Vacuum/pressure } \\
\text { Using chromated } \\
\text { Copper arsenate }\end{array}$} & Hard/Dry & 0.73 & 947.2) & 7 & (64.5) \\
\hline & & 1.00 & $(62.4)$ & $(58.3)$ & 18 \\
\hline & & 1.34 & 10.5 & 9 & 26.5 \\
\hline & & 1.72 & 23 & $(86.1)$ & 72.0 \\
\hline & Medium/Dry & 1.09 & $(35.1)$ & $(31.8)$ & $(46.1)$ \\
\hline & & 1.22 & $(38.8)$ & $(40.1)$ & $(53.5)$ \\
\hline & & 1.77 & $(41.3)$ & $(43.6)$ & $(64.5)$ \\
\hline & & 2.61 & $(52.6)$ & $(54.1)$ & (71.8) \\
\hline \multirow{8}{*}{$\begin{array}{l}\text { T2. Modified double } \\
\text { Diffusion employing } \\
\text { Copper sulphate, } \\
\text { Sodium dichromate } \\
\& \text { arsenic pentoxide }\end{array}$} & Hard/Dry & 1.58 & 26 & 7 & 38 \\
\hline & & 1.75 & 9 & 977.9) & 2 \\
\hline & & 0.93 & 49 & 13.5 & 48 \\
\hline & & 1.52 & 35 & 13 & 23 \\
\hline & Medium/Dry & 1.52 & 17 & $(60.6)$ & 969.4) \\
\hline & & 1.72 & $(56.7)$ & $(63.3)$ & (58.6) \\
\hline & & 2.06 & 18 & $(72.4)$ & (65.1) \\
\hline & & 1.35 & $(40.6)$ & $(53.8)$ & (58.9) \\
\hline
\end{tabular}




\begin{tabular}{|c|c|c|c|c|c|}
\hline $\begin{array}{l}\text { T3. Modified double } \\
\text { Diffusion using/ } \\
\text { Cooper sulphate } \\
\& \text { arsenic pentoxide }\end{array}$ & $\begin{array}{l}\text { Hard/Dry } \\
\text { Medium/Dry }\end{array}$ & $\begin{array}{l}0.42 \\
0.72 \\
1.19 \\
1.05 \\
0.51 \\
1.00 \\
2.70 \\
2.10\end{array}$ & $\begin{array}{l}(50.8) \\
(60.0) \\
(58.7) \\
(66.6) \\
(47.9) \\
(61.9) \\
(43.3) \\
(53.0)\end{array}$ & $\begin{array}{l}(56.2) \\
(66.0) \\
(72.1) \\
(65.3) \\
(53.4) \\
(42.6) \\
(50.8) \\
(45.1)\end{array}$ & $\begin{array}{l}(63.2) \\
(71.0) \\
(72.1) \\
(68.2) \\
(55.3) \\
958.3) \\
(58.3) \\
(52.1)\end{array}$ \\
\hline $\begin{array}{l}\text { T4. Modified double } \\
\text { Diffusion using } \\
\text { Copper sulphate } \\
\text { \& sodium dichromate }\end{array}$ & $\begin{array}{l}\text { Hard/Dry } \\
\text { Medium/Dry }\end{array}$ & $\begin{array}{l}0.96 \\
0.56 \\
1.34 \\
1.18 \\
2.05 \\
0.89 \\
1.57 \\
1.90\end{array}$ & $\begin{array}{c}13.5 \\
16 \\
12 \\
(52.9) \\
16 \\
(50.4) \\
9 \\
(31.5)\end{array}$ & $\begin{array}{c}(70.0) \\
8 \\
28 \\
(56.2) \\
7 \\
(64.7) \\
(59.9) \\
(45.8)\end{array}$ & $\begin{array}{c}19 \\
17 \\
(63.1) \\
(60.7) \\
16 \\
(48.6) \\
(39.5) \\
(45.9)\end{array}$ \\
\hline $\begin{array}{l}\text { T5. Modified double } \\
\text { Diffusion using } \\
\text { Copper sulphate, } \\
\text { Sodium dichromate } \\
\& \text { arsenic pentoxide }\end{array}$ & $\begin{array}{l}\text { Hard/Dry } \\
\text { Medium/Green }\end{array}$ & $\begin{array}{l}0.76 \\
0.69 \\
0.90 \\
0.72 \\
1.61 \\
0.95 \\
1.06 \\
1.24\end{array}$ & $\begin{array}{c}(68.1) \\
20 \\
(51.9) \\
(51.1) \\
(41.7) \\
(38.7) \\
(36.8) \\
(40.6)\end{array}$ & $\begin{array}{c}(60.2) \\
7 \\
(46.3) \\
7 \\
(32.7) \\
(34.8) \\
(34.6) \\
(35.8)\end{array}$ & $\begin{array}{c}18 \\
35 \\
7 \\
24 \\
(47.8) \\
(55.3) \\
(52.3) \\
(48.9)\end{array}$ \\
\hline $\begin{array}{l}\text { T6. Modified double } \\
\text { Diffusion using } \\
\text { Copper sulphate } \\
\& \text { arsenic pentoxide }\end{array}$ & $\begin{array}{l}\text { Hard/Dry } \\
\text { Medium/Green }\end{array}$ & $\begin{array}{l}0.24 \\
0.38 \\
0.65 \\
0.71 \\
0.35 \\
0.93 \\
0.85 \\
2.97\end{array}$ & $\begin{array}{l}(38.3) \\
(53.0) \\
(44.5) \\
(43.1) \\
933.3) \\
(35.3) \\
(39.2) \\
(41.1)\end{array}$ & $\begin{array}{l}(49.8) \\
(56.8) \\
(46.0) \\
(49.3) \\
(28.6) \\
(26.1) \\
(37.4) \\
(34.2)\end{array}$ & $\begin{array}{l}(45.3) \\
(73.1) \\
(62.8) \\
(57.9) \\
(32.6) \\
(39.2) \\
(40.7) \\
(42.5)\end{array}$ \\
\hline $\begin{array}{l}\text { T7. Modified double } \\
\text { Diffusion employing } \\
\text { Copper sulphate } \\
\text { \& sodium dichromate }\end{array}$ & $\begin{array}{l}\text { Hard/Green } \\
\text { Medium/Green }\end{array}$ & $\begin{array}{l}0.28 \\
0.25 \\
0.59 \\
0.55 \\
0.31 \\
0.59 \\
0.54 \\
0.49\end{array}$ & $\begin{array}{c}9 \\
(58.3) \\
(47.9 .) \\
(56.7) \\
(38.8) \\
(34.0) \\
(30.4) \\
(45.4)\end{array}$ & $\begin{array}{c}(51.4) \\
14 \\
(57.8) \\
7 \\
(35.3) \\
(31.6) \\
(35.4) \\
(44.6)\end{array}$ & $\begin{array}{c}7 \\
16 \\
(49.8) \\
(65.3) \\
(45.1) \\
(50.6) \\
(34.7) \\
(48.7)\end{array}$ \\
\hline $\begin{array}{l}\text { T8. Simple diffusion } \\
\text { With PQ } 56\end{array}$ & $\begin{array}{l}\text { Hard/Dry } \\
\text { Medium/Dry }\end{array}$ & $\begin{array}{l}0.01 \\
0.02 \\
0.03 \\
0.04 \\
0.02 \\
0.01 \\
0.03 \\
0.04 \\
\end{array}$ & $\begin{array}{c}(36.0) \\
(17.5) \\
7 \\
(44.5) \\
(16.4) \\
(30.1) \\
(18.6) \\
(16.8) \\
\end{array}$ & $\begin{array}{l}(29.0) \\
(26.1) \\
(29.2) \\
(28.2) \\
(20.0) \\
(19.0) \\
(19.0) \\
(20.0)\end{array}$ & $\begin{array}{l}(27.1) \\
(20.5) \\
(33.6) \\
(38.8) \\
(13.4) \\
(13.4) \\
(12.2) \\
(15.7)\end{array}$ \\
\hline
\end{tabular}




\begin{tabular}{|l|l|c|c|c|c|}
\hline T9. Simple diffusion & Hard/Dry & 0.94 & $(23.0)$ & $(26.7)$ & $(24.2)$ \\
Using Protek Q & & 0.78 & $(23.5)$ & $(15.6)$ & $(26.2)$ \\
& & 0.76 & $(35.8)$ & $(23.5)$ & $(27.2)$ \\
& & 0.90 & $(49.3)$ & $(27.8)$ & $(37.4)$ \\
& Medium/Dry & 1.51 & $(14.9)$ & $(10.6)$ & $(16.9)$ \\
& & 1.89 & $(10.2)$ & $911.6)$ & $(11.0)$ \\
& & 1.59 & $(19.6)$ & $(10.1)$ & $(11.0)$ \\
& & 2.07 & $(17.7)$ & $911.2)$ & $(13.4)$ \\
& & & & & \\
\hline T10. Simple diffusion with & Hard/Dry & 0.92 & $(34.5)$ & $(37.5)$ & $(47.3)$ \\
& & 0.85 & $(36.5)$ & $(36.9)$ & $(51.4)$ \\
& & 0.80 & $(42.8)$ & $(42.4)$ & $(61.8)$ \\
& & 0.76 & 4 & $(49.8)$ & 6 \\
& Medium/Dry & 1.83 & $(22.5)$ & $(25.9)$ & $(29.0)$ \\
& & 1.80 & $(26.6)$ & $(25.7)$ & $(31.8)$ \\
& & 1.78 & $(39.2)$ & $(32.0)$ & $(35.2)$ \\
& & 1.75 & $(37.4)$ & $(33.9)$ & $(37.2)$ \\
& & & & & $(22)$ \\
\hline T11. Control & & - & $(13.8)$ & $(20.6)$ & $(22.7)$ \\
& Hard/Dry & - & $(11.2)$ & $(7.6)$ & $912.1)$ \\
& Medium/Dry & & & & \\
\hline
\end{tabular}

$1 /$ - Mean of 10 samples.

2/- Based on the rating: sound-100; trace of decay-W moderate decay-70; heavy decay-40; and failure- 0 .

Figure in parenthesis represents the average fife (in months) of a treatment group after all the replicate stakes failed.

It was noted that the performance of the samples receiving simple diffusion treatments (T8, T9 and T10) was inferior than the ones treated by modified double diffusion method (T2, T3, T4, T5, T6, and T7). Furthermore, the application of Copper sulphate, Sodium dichromate and Arsenic pentoxide (T2 and T5) to the specimens showed better performance than employing only a combination of Copper sulphate and Arsenic pentoxide (T3 and T6) or Copper Sulphate and Sodium dichromate T4 and T7).

Untreated (Control) high and mediurn density samples had field lives of 13.8 to 22.7 months (1.2 to 1.9 years) and 7.6 to 12.1 months ( 0.6 to 1 year), respectively.

\section{Stake test (Graveyard No. 3).}

This test evaluates the effectiveness of double diffusion treatment when applied to green coconut wood stakes. The process involved the diffusion of mixture of $13 \%$ Copper sulphate and $2 \%$ Arsenic pentoxide solution followed by soaking of wood specimens into 5\% Ammonia solution.

The diffusion periods were 1, 2, 3, 4 and 5 weeks while soaking time were 1, 2, 3, and 4 days. After ammonia treatment the boards were air dried for 3 weeks prior to graveyard testing.

The treated stakes were installed in PCA-ZRC graveyard in December, 1983.

Results of assessment on the performance of the treated stakes after 5 years in ground contact in shown in Table 3. In general, the performance of the stakes improved with increasing diffusion period suggesting that the preservative solution diffused deeper into the cavities of the wood with 
longer diffusion period. However, increasing soaking time in Ammonia solution did not improve the field performance of the treated specimens.

Table 3. Performance of coconut stakes at 5 levels of diffusion period and 4 levels of soaking time. 1/

\begin{tabular}{|c|r|r|r|r|}
\hline DIFFUSION & \multicolumn{4}{|c|}{ SOAKING TIME (DAYS) } \\
\cline { 2 - 5 } PERIOD (weeks) & \multicolumn{1}{|c|}{1} & \multicolumn{1}{|c|}{2} & \multicolumn{1}{c|}{4} \\
\hline 1 & $37.5^{*}(20) 70^{* *}$ & $44.5^{*}(20) 70^{* *}$ & $43.8^{*}(0) 0^{* *}$ & $36.2(0)^{* *}$ \\
2 & $58^{*}(40) 95^{* *}$ & $55^{*}(80) 80^{* *}$ & $46.8^{*}(20) 90^{* *}$ & $53.3^{*}(40) 80^{* *}$ \\
3 & $(100) 75^{* *}$ & $(100) 88^{* *}$ & $63^{*}(80) 75^{* *}$ & $55^{*}(80) 72.5^{* *}$ \\
4 & $(100) 86^{* *}$ & $63^{*}(80) 82.5^{* *}$ & $(100) 80^{* *}$ & $55^{*}(80) 72.5^{* *}$ \\
5 & $(100) 86^{* *}$ & $(100) 96^{* *}$ & $(100) 92^{* *}$ & $55(80) 80^{* *}$ \\
& & & & \\
\hline
\end{tabular}

1/Five replicate stakes per treatment combination. Number with *, ( ) and ** represent mean field life (in months) of failed stakes, the percentage and performance rating of remaining stakes, respectively. **Based on the rating: sound -100 ; trace of decay-90; heavy decay- 40 ; and failed due to decay- 0 .

\section{Pole Stub test.}

CCA-treated pole stubs. - This test aims to determine the performance of cocowood pole stubs under graveyard condition. Thirty untreated and treated pole stubs were installed in PCA-DRC graveyard with the treated ones receiving four levels of preservative retention of 10.50, 14.50, 18.00 and $20.94 \mathrm{~kg} / \mathrm{m} 3$. Each preservative retention had six replicate pole stubs.

The field performance of the pole stubs after $121 / 2$ years, in ground contact is shown in Table 4. The treated stubs with preservative retention of over $20 \mathrm{~kg} / \mathrm{m} 3$ (T4) had average performance rating of $91.1 \%$ which showed slight decay at groundline zone but one of the six replicate-stubs was in sound condition. The pole stubs receiving $18 \mathrm{~kg} / \mathrm{m} 3$ retention (T3) were observed to have mean performance rating of $83.3 \%$ indicating 2 pole stubs with active decay and 4 others having slight decay. The test pole stubs with preservative retention of $10.5 \mathrm{~kg} / \mathrm{m} 3$ (Tl) and $14.5 \mathrm{~kg} / \mathrm{m} 3$ (T2) were noted of having active to severe decay. In contrast, untreated pole stubs had mean field life of only 3.5 years.

\section{Pressure and non-pressure treatment of pole stubs}

This trial is aimed to determine the comparative effectiveness of preservative systems when applied to round coconut pole stubs. The preservative systems consisted of pressure treatment employing $2 \%$ and $6 \%$ CCA solution, modified double diffusion using a $4.8 \%$ mixture of Copper sulphate, Arsenic pentoxide and Sodium dichromate solution, and hot and cold bath method with coal tar. The treated pole stubs were installed at the PCA-ZRC graveyard.

Results of assessment of the field performance of treated cocowood pole stubs after 8 years in ground contact and exposed conditions (Table 5) showed that the pressure-treated samples with CCA retention of $17.75 \mathrm{~kg} / \mathrm{m} 3$ (T2) were observed to have active decay at groundline zone while the other specimens receiving CCA retention of $5.05 \mathrm{~kg} / \mathrm{m} 3$ (T1) indicated severe decay in all the wood surfaces in contact with ground. Samples treated by modified double diffusion having preservative retention of $7.85 \mathrm{~kg} / \mathrm{m} 3$ (T3) including the pole stubs treated by hot and cold bath with retention of $13.08 \mathrm{~kg} / \mathrm{m} 3$ (T4) were observed to be in advanced decay. 


\section{E. Exposure test}

This study aims to evaluate the effectiveness of different preservatives and treatment methods when applied to coconut shingles as roofing material. The preservatives on test were Protek Q, CCA, PO 56, Copper sulphate + Sodium dichromate, Cuprinol, PQ 675, and Copper sulphate + Sodium dichromate + Arsenic pentoxide. Treatment methods employed were brushing, simple diffusion, modified double diffusion, hot and cold bath, and vacuum-pressure.

Table 4. Performance of CCA-treated cocowood pole stubs after 12 1/2 years of field exposure (DRC graveyard). 1/

\begin{tabular}{|c|c|}
\hline $\begin{array}{c}\text { PRESERVATIVE RETENTION } \\
(\mathrm{kg} / \mathrm{m} 3)\end{array}$ & $\begin{array}{c}\text { PERFORMANCE RATING 2/ } \\
\end{array}$ \\
\hline Control (untreated) & Mean field life -3.5 years \\
T1-10.50 & 60.0 \\
T2-14.50 & 66.7 \\
T3-18.00 & 83.3 \\
T4-20.94 & 91.1 \\
\hline
\end{tabular}

$1 /$ - Mean of 6 pole stubs.

2/ - Based on the rating: Sound- $100 \%$, slight decay- $90 \%$, active decay-70\%, severe decay- $40 \%$ and failed due to decay- 0 .

Table 5. Performance of treated cocowood pole stubs after 8 years of field exposure (ZRC graveyard). 1/

\begin{tabular}{|l|c|c|}
\hline \multicolumn{1}{|c|}{$\begin{array}{c}\text { TREATMENT } \\
\text { METHOD }\end{array}$} & $\begin{array}{c}\text { PRESERVATIVE/RETENTION } \\
(\mathrm{kg} / \mathrm{m} 3)\end{array}$ & $\begin{array}{c}\text { PERFORMANCE RATING 2/ } \\
(\%)\end{array}$ \\
\hline & & 36.7 \\
Vacuum-pressure & $\mathrm{CCA} / 5.05$ & 70.0 \\
Vacuum-pressure & $\mathrm{CCA} / 17.75$ & 26.7 \\
Modified double diffusion & $\mathrm{Cu}+\mathrm{Cr}+\mathrm{As} / 7.85$ & 13.3 \\
Hot and cold bath & $\mathrm{Coal}$ tar/13.08 & \multicolumn{2}{|c}{} \\
\hline
\end{tabular}

$1 /$ - Mean of 3 pole stubs.

2/- Based on the rating: Sound-100\%, slight decay- $90 \%$, active decay-70\%, severe decay- $40 \%$ and failed due to decay-0.

The treated shingles together with the control were exposed to weather condition (but not in ground contact) at the PCA-ZRC graveyard in January, 1980.

Results of exposure test (Table 6) showed that the shingles treated with Protek Q by hot and cold bath method (T1) and with mixture of Copper sulphate and Sodium dichromate by simple diffusion (T4) each failed after 7 years of exposure. PQ 56-treated cocowood shingles (T3) by hot and cold bath were decayed 6 years while the control (T8) was destroyed by decay fungi after 5 years.

The promising treatment was the shingles treated with combination of Copper sulphate, Sodium dichromate and Arsenic pentoxide (T7) by modified double diffusion process which was still in good condition after 8 years of exposure. Treatment with Chromated copper arsenate by vacuum-pressure method (T2) showed erosion of surface fibers and presence of decay. Likewise, the 
shingles treated with PQ 675 (T6) by simple diffusion process were observed to have slight erosion of surface fibers but the appearance was generally good while Cuprinol-treated shingles (T5) were moderately decayed and exposed surface was badly eroded.

Table 6. Condition of cocowood shingles installed at ZRC graveyard in January, 1980.

\begin{tabular}{|l|l|}
\hline \multicolumn{1}{|c|}{$\begin{array}{c}\text { TREATMENT } \\
\text { (Preservative }\end{array}$} & \multicolumn{1}{|c|}{ CONDITION } \\
\hline T1-Protek Q & Failed after 7 years of outside exposure. \\
\hline T2-Chromated copper arsenate & Erosion of surface fibers and slightly decayed. \\
\hline T3-PQ 56 & Failed after 6 years of outside exposure. \\
\hline T4-Copper sulphate + Sodium dichromate & Failed after 7 years of outside exposure. \\
\hline T5-Cuprinol & $\begin{array}{l}\text { Moderately decayed and surface fibers badly } \\
\text { Eroded. }\end{array}$ \\
\hline T6-PQ 675 & $\begin{array}{l}\text { Slight erosion of surface fiber but with good } \\
\text { Appearance. }\end{array}$ \\
\hline T7-Copper sulphate + Sodium dichromate & Still in good condition \\
\hline T8-Control (No treatment) & Failed after 5 years of outside exposure. \\
\hline
\end{tabular}

\section{SERVICE TESTS}

\section{A. Pressure-treated poles}

CCA-treated service poles were installed in May, 1976 and January, 1977 at the PCA-Davao Research Center compound and along the diversion road in Panacan, Davao City. The poles received mean dry salt retention of $18 \mathrm{~kg} / \mathrm{m} 3$.

Result of assessment on the performance of the poles installed in PCA-DRC (Table 7) showed that two service poles out of the 12 poles installed were severely decayed (performance rating of 40\%) at groundline zone while the remaining ones were observed to have active decay (performance rating of $70 \%)$.

On the other hand, the nineteen poles installed in Panacan, Davao City (Table 8) indicated that 3 poles had service life of 11 years, another 2 poles with 12 years service life, 8 were rated to have active decay, 5 were slightly decayed and 1 pole was still in good condition.

\section{B. Non-pressure treated poles}

Treatment with cocowood poles by non-pressure process was undertaken and installed in PCA-ZRC compound between 1977 and 1981 to service a 220-volt electric transmission lines. Result of assessment of the service poles is presented in Table 9. 
Table 7. Performance of CCA-treated cocowood poles after $121 / 2$ years of service (installed in May, 1976 at PCA-DRC Compound).

\begin{tabular}{|c|c|}
\hline POLE NUMBER & PERFORMANCE RATING 1/ \\
& $(\%)$ \\
\hline $35-\mathrm{y}$ & 70 \\
$12-\mathrm{g}$ & 70 \\
$22-\mathrm{y}$ & 70 \\
$4-\mathrm{g}$ & 70 \\
$30-\mathrm{y}$ & 70 \\
$2-\mathrm{g}$ & 40 \\
$27-\mathrm{y}$ & 70 \\
$19-\mathrm{y}$ & 70 \\
$33-\mathrm{y}$ & 70 \\
$11-\mathrm{g}$ & 70 \\
$31-\mathrm{g}$ & 40 \\
$26-\mathrm{g}$ & 70 \\
\hline
\end{tabular}

1/ - Based on the rating: Sound- $100 \%$, slight decay- $90 \%$, active decay- $70 \%$, severe decay- $40 \%$ and failed due to decay- 0 .

Table 8. Performance of CCA-treated cocowood poles after 12 years of service (36 feet poles installed in January, 1977 at Diversion road Panacan, Davao City).

\begin{tabular}{|c|c|}
\hline POLE NUMBER & $\begin{array}{c}\text { PERFORMANCE RATING 1/ } \\
(\%)\end{array}$ \\
\hline 63304 & Service life-11 years \\
63305 & Service life-11 years \\
63306 & Service life-11 years \\
63308 & 70 \\
63309 & 70 \\
63310 & 70 \\
63311 & 70 \\
63312 & 70 \\
63313 & 70 \\
63748 & 90 \\
63750 & 90 \\
63751 & 70 \\
63752 & 100 \\
63753 & 90 \\
63754 & 90 \\
63755 & Service life-12 years \\
63756 & Service life-12 years \\
\hline
\end{tabular}


1/- Based on the rating: Sound- $100 \%$, slight decay- $90 \%$ active decay- $70 \%$, severe decay- $40 \%$ and failed due to decay- 0 .

Table 9. Conditions of service poles treated by non-pressure processes.

\begin{tabular}{|l|c|c|c|l|}
\hline $\begin{array}{c}\text { TREATMENT } \\
\text { METHOD }\end{array}$ & $\begin{array}{c}\text { YEAR } \\
\text { INSTALLATED }\end{array}$ & $\begin{array}{c}\text { ORIGINAL } \\
\text { NUMBER }\end{array}$ & $\begin{array}{c}\text { NUMBER OF } \\
\text { POLES FAILED }\end{array}$ & $\begin{array}{c}\text { CONDITIONS } \\
\text { OF } \\
\text { REMAINING } \\
\text { POLES }\end{array}$ \\
\hline $\begin{array}{l}\text { 1. Charring and } \\
\text { brushing with }\end{array}$ & 1977 & 17 & 17 & - \\
Coal tar & 1978 & 10 & 8 & Advance decay \\
\hline 2. Modified double & 1978 & 10 & 6 & Moderate decay \\
diffusion with & 1981 & 20 & 0 & Slight decay \\
Cu + Cr + As & & & \\
\hline
\end{tabular}

All 17 poles treated by charring and brushing with coal tar which were installed in 1977 failed due to combined attack of decay fungi and termites. Eight out of 10 poles receiving similar treatment installed in 1978 were destroyed by the same wood destroying organisms while the remaining 2 poles were in advanced decay with heavy attack of termites.

In contrast, 6 of the 10 poles treated with combination of Copper sulphate, Sodium dichromate and Arsenic pentoxide by modified double diffusion which were service-tested in 1978 failed while the remaining poles were observed to have moderate decay. Ail the 20 poles treated by the same process installed in 1981 were still serviceable but they were slightly attacked by decay fungi.

\section{Cocowood houses}

Assessment on the performance of cocolumber used in building construction revealed the following results:

1. Six of the 12 units experimental houses with double walls built in 1979 showed that the untreated medium density materials for inside walls were heavily attacked by drywood as well as subterranean termites. Likewise the untreated materials in constant contact with moisture such as doors and door jambs for bathrooms in ail the houses continued to deteriorate and 10 of these housing components are due for replacement. In contrast, ail the treated cocowood materials such as post, fascia boards, outside walls, girts, etc. were still in sound condition after 9 years of service.

2. The six units low-cost houses constructed in 1980 revealed that the CCA-treated wood posts directly in contact with the ground were slightly decayed. The attack of subterranean termites in the posts observed in one of the houses last year was discontinued due to adequate protection of the material by treatment with CCA which contained Arsenic. One of the houses which had leaking roof and was abandoned for almost a year showed advanced deterioration of its girts, floor joists, floors, rafters, purlins and fascia boards. However, it had been repaired and a new occupant was assigned to this house.

3. The 6 units UNIDO-funded houses built in 1984 were generally in good condition. However, four of the houses were leaking due to severe cracking and splitting of the cocowood roof 
shingles. Installation of corrugated G. L sheets on top of the shingles appeared to be the only way to solve this problem. 
4. The cocowood guest house constructed in 1983 at PCA-Albay Research Center was assessed and the results are as follows :

a. The external walls and floors, which were in constant contact with moisture during rainy season indicated erosion of surface fibers and presence of decay.

b. The internal walls were observed to have marked deviation from the original appearance with some boards exhibiting erosion of the surface fibers.

c. The girts, floor joists, studs and other wood components of the building with no proper ventilation and always dark were suspected of having attacked by termites.

\section{REFERENCES}

PALOMAR, R.N. 1979. Pressure impregnation of sawn coconut lumber for building construction materials. Phil. J. Coco. Studs. 4(4) : 15-28.

PALOMAR, R.N. 1979. Preservation techniques of coconut (Cocos nucifera L.) palm timber for electric power/telecommunication poles and fence posts. 1979 Annual Report. PCA-Agricultural Research Branch.

PALOMAR, R.N. and V.K. SULC. 1981. Preservative treatment and performance of coconut palm timber. Seminar Proceedings, PACWOOD and Hickson's Timber Preservation, Ltd., Philippines.

PALOMAR, R.N, P. JENSEN and V.K. SULC. 1989. Exposure test of surface-treated sawn coconut timber. CORD, 5(1): 93107.

PALOMAR, R.N. and J.O. SIOPONGCO. 1988. Technology manual on coconut wood as construction material. UNDP/UNIDO Regional Network in Asia-Pacific for low-cost Building Materials Technologies and Construction Systems.

SULC, V.K. 1976. Coconut stem utilization at the Philippine Coconut Authority - Zamboanga Research Center. Seminar Proceedings, Coconut Stern Utilization, Tonga, 1976.

SULC, V.K. and R.N. PALOMAR. 1980. A report on the 1980 inspection of CCA-treated coconut electric poles and pole stubs. Unpublished. PCA-Zamboanga Research Center. 